\title{
Design New Online Tuning Intelligent Chattering Free Fuzzy Compensator
}

\author{
Alireza Khalilian, Farzin Piltan, Omid Avatefipour, Mahmoud Reza Safaei Nasrabad, Ghasem \\ Sahamijoo \\ Institute of Advance Science and Technology, Intelligent control and Robotics Lab. IRAN SSP, Shiraz, Iran \\ Email: Piltan_f@iranssp.com, http://WWW.IRANSSP.COM
}

\begin{abstract}
This research is focused on proposed adaptive fuzzy sliding mode algorithms with the adaptation laws derived in the Lyapunov sense. The stability of the closed-loop system is proved mathematically based on the Lyapunov method. Adaptive MIMO fuzzy compensate fuzzy sliding mode method design a MIMO fuzzy system to compensate for the model uncertainties of the system, and chattering also solved by new adaption method. Since there is no tuning method to adjust the premise part of fuzzy rules so we presented a scheme to online tune consequence part of fuzzy rules. Classical sliding mode control is robust to control model uncertainties and external disturbances. A sliding mode method with a switching control low guarantees the stability of the certain and/or uncertain system, but the addition of the switching control low introduces chattering into the system. One of the main targets in this research to reduce or eliminate chattering is to insert online tuning method. Classical sliding mode control method has difficulty in handling unstructured model uncertainties. One can overcome this problem by combining a sliding mode controller and artificial intelligence (e.g. fuzzy logic). To approximate a time-varying nonlinear dy namic system, a fuzzy system requires a large amount of fuzzy rule base. This large number of fuzzy rules will cause a high computation load. The addition of an adaptive law to a fuzzy sliding mode controller to online tune the parameters of the fuzzy rules in use will ensure a moderate computational load. The adaptive laws in this algorithm are designed based on the Lyapunov stability theorem. Asymptotic stability of the closed loop system is also proved in the sense of Lyapunov. This method is applied to continuum robot manipulator to have the best performance.
\end{abstract}

Index Terms - Adaptive Fuzzy Sliding Mode Algorithm, Continuum Robot, Lyapunov Based, Adaptive MIMO Fuzzy Compensate Fuzzy Sliding Mode Algorithm, Chattering Phenomenon, Fuzzy Logic Controller, Adaptive Law.

\section{INTRODUCTION AND BACKGROUND}

The first person who used the word robot was Karel Capek in 1920 in his satirical play, R.U.R (Rossum's Universal Robots). The first person who used the word robotics was the famous author, Issac Asimov along with three fundamental rules. Following World War II, the first industrial robot manipulator have been installation at General Motors in 1962 for the automation. In 1978 the PUMA (Programmable Universal Mach ine for Assembly) and in 1979 the SCARA (Selective Compliance Assembly Robot Arm) were introduced and they were quickly used in research laboratories and industries. According to the MSN Learning \& Research," 700000 robots were in the industrial world in 1995 and over 500000 were used in Japan, about 120000 in Western Europe, and 60000 in the United States [1- 6]." Research about mechanical parts and control methodologies in robotic system is shown; the mechanical design, type of actuators, and type of systems drive play important roles to have the best performance controller. More over types of kinematics chain, i.e., serial Vs. parallel manipulators, and types of connection between link and join actuators, i.e., highly geared systems Vs. direct-drive systems are played important roles to select and design the best acceptable performance controllers [7-11]. A serial link continuum robot is a sequence of joints and lin ks which begins with a base frame and ends with an end-effector. This type of robot manipulators, comparing with the load capacitance is more weightily because each link must be supported the weights of all next links and actuators between the present link and end-effector[12-18]. Serial continuum robot manipulators have been used in medical application, and also in research laboratories. One of the most important classifications in controlling the robot manipulator is how the links have connected to the actuators. This classification divides into two main groups: highly geared (e.g., 200 to 1) and direct drive (e.g., 1 to 1 ). High gear ratios reduce the nonlinear coupling dynamic parameters in robot manipulator. In this case, each joint is modeled the same as SISO systems In high gear robot manipulators which generally are used in industry, the couplings are modeled as a disturbance for SISO systems. Direct drive increases the coupling of nonlinear dynamic parameters of robot manipulators. This effect should be considered in the design of control systems. As a result some control and robotic researchers' works on nonlinear robust controller design[19-24]. Although most of continuum robot manipulator is high gear but this research focuses on design MIMO controller.

In modern usage, the word of control has many meanings, this word is usually taken to mean regulate, direct or command. The word feedback plays a vital role in the advance engineering and science. The conceptual frame work in Feed-back theory has developed only since world war II. In the twentieth century, there was a rapid growth in the application of feedback controllers in process industries. According to Ogata, to do the first significant work in three-term or PID controllers which Nicholas Minorsky worked on it by automatic controllers in 1922. In 1934, Stefen Black was invention of the 
feedback amplifiers to develop the negative feedback amplifier[25-40]. Negative feedback invited communications engineer Harold Black in 1928 and it occurs when the output is subtracted from the input. Automatic control has played an important role in advance science and engineering and its extreme importance in many industrial applications, i.e., aerospace, mechanical engineering and robotic systems. The first significant work in automatic control was James Watt's centrifugal governor for the speed control in motor engine in eighteenth century [41-48]. There are several methods for controlling a robot manipulator, which all of them follow two common goals, namely, hardware/software implementation and acceptable performance. However, the mechanical design of robot manipulator is very important to select the best controller but in general two types schemes can be presented, namely, a joint space control schemes and an operation space control schemes[49-55]. Joint space and operational space control are closed loop controllers which they have been used to provide robustness and rejection of disturbance effect. The main target in joint space controller is to design a feedback controller which the actual motion $\left(q_{a}(t)\right)$ and desired motion $\left(q_{d}(t)\right)$ as closely as possible. This control problem is classified into two main groups. Firstly, transformation the desired motion $X_{d}(t)$ to joint variable $q_{d}(t)$ by inverse kinematics of robot manipulators [34-50]. This control include simple PD control, PID control, inverse dynamic control, Lyapunov-based control, and passivity based control that explained them in the following section. The main target in operational space controller is to design a feedback controller to allow the actual end-effector motion $X_{a}(t)$ to track the desired endeffector motion $X_{d}(t)$. This control methodology requires a greater algorithmic complexity and the inverse kinematics used in the feedback control loop. Direct measurement of operational space variables are very expensive that caused to limitation used of this controller in industrial robot manipulators[53-55]. One of the simplest ways to analysis control of multiple DOF robot manipulators are analyzed each joint separately such as SISO systems and design an independent joint controller for each joint. In this controller, inputs only depends on the velocity and displacement of the corresponding joint and the other parameters between joints such as coupling presented by disturbance input. Joint space controller has many advantages such as one type controllers design for all joints with the same formulation, low cost hardware, and simple structure.

A nonlinear methodology is used for nonlinear uncertain systems (e.g., robot manipulators) to have an acceptable performance. These controllers divided into six groups, namely, feedback linearization (computedtorque control), passivity-based control, sliding mode control (variable structure control), artificial intelligence control, lyapunov-based control and adaptive control[120]. Sliding mode controller (SMC) is a powerful nonlinear controller which has been analyzed by many researchers especially in recent years. This theory was first proposed in the early 1950 by Emelyanov and several co-workers and has been extensively developed since then with the invention of high speed control devices [1-23]. The main reas on to opt for this controller is its acceptable control performance in wide range and solves two most important challenging topics in control which names, stability and robustness [24-55]. Sliding mode controller is divided into two main sub controllers: discontinues controller $\left(\boldsymbol{\tau}_{\text {dis }}\right)$ and equivalent controller $\left(\boldsymbol{\tau}_{\boldsymbol{e q}}\right)$. Discontinues controller causes an acceptable tracking performance at the expense of very fast switching. In the theory of infinity fast switching can provide a good tracking performance but it also can provide some problems (e.g., system instability and chattering phenomenon). After going toward the sliding surface by discontinues term, equivalent term help to the system dynamics match to the sliding surface[1- 6]. However, this controller used in many applications but, pure sliding mode controller has following challenges: chattering phenomenon, and nonlinear equivalent dynamic formulation [20]. Chattering phenomenon can causes some problems such as saturation and heat the mechanical parts of robot manipulators or drivers. To reduce or eliminate the chattering, various papers have been reported by many researchers which classified into two most important methods: boundary layer saturation method and estimated uncertainties method [1, 10-14]. In boundary layer saturation method, the basic idea is the discontinuous method replacement by saturation (linear) method with s mall neighborhood of the switching surface. This replacement caused to increase the error performance against with the considerable chattering reduction.

In recent years, artificial intelligence theory has been used in sliding mode control systems. Neural network, fuzzy logic, and neuro-fuzzy are synergically combined with nonlinear classical controller and used in nonlinear, time variant, and uncertainty plant (e.g., robot manipulator). Fuzzy logic controller (FLC) is one of the most important applications of fuzzy logic theory. This controller can be used to control nonlinear, uncertain, and noisy systems. This method is free of some model-based techniques as in classical controllers. As mentioned that fuzzy logic application is not only limited to the modelling of nonlinear systems [31-36]but also this method can help engineers to design easier controller. Control robot arm manipulators using classical controllers are based on manipulator dynamic model. These controllers often have many problems for modelling. Conventional controllers require accurate information of dynamic model of robot manipulator, but these models are multi-input, multi-output and non-linear and calculate accurate model can be very difficult. When the system model is unknown or when it is known but complicated, it is difficult or impossible to use classical mathematics to process this model[32]. The main reasons to use fuzzy logic technology are able to give approximate recommended solution for unclear and complicated systems to easy understanding and flexible. Fuzzy logic provides a method which is able to model a 
controller for nonlinear plant with a set of IF-THEN rules, or it can identify the control actions and describe them by using fuzzy rules. It should be mentioned that application of fuzzy logic is not limited to a system that's difficult for modeling, but it can be used in clear systems that have complicated mathematics models because most of the time it can be shortened in design but there is no high quality design just sometimes we can find design with high quality. Besides using fuzzy logic in the main controller of a control loop, it can be used to design adaptive control, tuning parameters, working in a parallel with the classical and non classical control method [3239]. The applications of artificial intelligence such as neural networks and fuzzy logic in modelling and control are significantly growing especially in recent years. For instance, the applications of artificial intelligence, neural networks and fuzzy logic, on robot arm control have reported in [40-55].

In various dynamic parameters systems that need to be training on-line adaptive control methodology is used. Adaptive control methodology can be classified into two main groups, namely, traditional adaptive method and fuzzy adaptive method. Fuzzy adaptive method is used in systems which want to training parameters by expert knowledge. Traditional adaptive method is used in systems which some dynamic parameters are known. In this research in order to solve disturbance rejection and uncertainty dynamic parameter, adaptive method is applied to artificial sliding mode controller. For nonlinear dynamic systems (e.g., robot manipulators) with various parameters, adaptive control technique can train the dynamic parameter to have an acceptable controller performance. Calcu late several scale factors are common challenge in classical sliding mode controller and fuzzy logic controller, as a result it is used to adjust and tune coefficient. Research on adaptive fuzzy control is significantly growing, for instance, different adaptive fuzzy controllers have been reported in [40, 53-55]. This paper is organized as follows; second part focuses on the modeling dynamic formulation based on Lagrange methodology, fuzzy logic methodology and sliding mode controller to have a robust control. Third part is focused on the methodology which can be used to reduce the error, increase the performance quality and increase the robustness and stability. Simulation result and discussion is illustrated in forth part which based on trajectory following and disturbance rejection. The last part focuses on the conclusion and compare between this method and the otherones.

\section{THEORY}

SLIDING MODE CONTROLLER: One of the significant challenges in control algorithms is a linear behavior controller design for nonlinear systems. When system works with various parameters and hard nonlinearities this technique is very useful in order to be implemented easily but it has some limitations such as working near the system operating point[2]. Some of robot manipulators which work in industrial processes are controlled by linear PID controllers, but the design of linear controller for robot manipulators is extremely difficult because they are nonlinear, uncertain and MIMO[33-55]. To reduce above challenges the nonlinear robust controllers is used to systems control. One of the powerful nonlinear robust controllers is sliding mode controller (SMC), although this controller has been analyzed by many researchers but the first proposed was in the 1950 [7].This controller is used in wide range areas such as in robotics, in control process, in aerospace applications and in power converters because it has an acceptable control performance and solve some main challenging topics in control such as resistivity to the external disturbance.

The dynamic formulation of continuum robot manipulate can be written by the following equation

$$
\boldsymbol{\tau}=\boldsymbol{D}(\boldsymbol{q}) \ddot{\boldsymbol{q}}+\boldsymbol{V}(\boldsymbol{q}, \dot{\boldsymbol{q}}) \dot{\boldsymbol{q}}+\boldsymbol{G}(\boldsymbol{q})
$$

the lyapunov formulation can be written as follows,

$$
V=\frac{1}{2} S^{T} . D . S
$$

the derivation of $V$ can be determined as,

$$
\dot{V}=\frac{1}{2} S^{T} \cdot \dot{D} \cdot S+S^{T} D \dot{S}
$$

the dynamic equation of robot manipu lator can be written based on the sliding surface as

$$
D \dot{S}=-V S+D \dot{S}+V S+G-\tau
$$

It is assumed that

$$
S^{T}(\dot{D}-2 V) S=0
$$

by substituting (4) in (3)

$$
\begin{aligned}
& \dot{V}=\frac{1}{2} S^{T} \dot{D} S-S^{T} V S+S^{T}(D \dot{S}+V S+G- \\
& \tau)=S^{T}(D \dot{S}+V S+G-\tau)
\end{aligned}
$$

suppose the control input is written as follows

$$
\begin{aligned}
\widehat{\boldsymbol{\tau}}=\widehat{\boldsymbol{\tau}_{e q}}+\widehat{\boldsymbol{\tau}_{\text {dis }}=} & {\left[\widehat{D^{-1}}(\widehat{V}+\widehat{G})+\dot{S}\right] \widehat{D} } \\
& +K \cdot \operatorname{sgn}(S)+K_{v} S
\end{aligned}
$$

by replacing the equation (7) in (6)

$$
\begin{aligned}
& \dot{V}=S^{T}(D \dot{S}+V S+G-\widehat{D} \dot{S}-\widehat{V} S-\widehat{G}- \\
& K_{v} S-K \operatorname{sgn}(S)=S^{T}(D \dot{S}+\widetilde{V} S+\widetilde{G}- \\
& \left.K_{v} S-K \operatorname{sgn}(S)\right)
\end{aligned}
$$

It is obvious that

$$
\begin{aligned}
& \left|\widetilde{D} \dot{S}+\widetilde{V} S+\widetilde{G}-K_{v} S\right| \leq|\widetilde{D} \dot{S}|+|\widetilde{V} S|+ \\
& |\widetilde{G}|+\left|K_{v} S\right|
\end{aligned}
$$

the Lemma equation in robot manipulator system can be written as follows

$$
\begin{aligned}
& K_{u}=\left[|\widetilde{D} \dot{S}|+|V S|+|G|+\left|K_{v} S\right|+\eta\right]_{i} \\
& , i=1,2,3,4, \ldots
\end{aligned}
$$

the (5) can be written as 


$$
K_{u} \geq\left|\left[\widetilde{D} \dot{S}+V S+G-K_{v} S\right]_{i}\right|+\eta_{i}
$$

therefore, it can be shown that

$$
\dot{V} \leq-\sum_{i=1}^{n} \eta_{i}\left|S_{i}\right|
$$

Based on above discussion, the control law for a multi degrees of freedom robot manipulator is written as:

$$
\boldsymbol{U}=\boldsymbol{U}_{e q}+\boldsymbol{U}_{\boldsymbol{r}}
$$

Where, the model-based component $\boldsymbol{U}_{\boldsymbol{e q}}$ is the nominal dynamics of systems and $\boldsymbol{U}_{\boldsymbol{e q}}$ can be calculate as follows:

$$
U_{e q}=\left[D^{-1}(f+C+G)+\dot{S}\right] D
$$

and $\boldsymbol{U}_{\text {SWITCH}}$ is computed as;

$$
U_{\text {sat }}=K \cdot \mathbf{S G N}(S / \varnothing)
$$

by replace the formulation (15) in (13) the control output can be written as;

$$
U=U_{e q}+K . \operatorname{SGN}(S / \varnothing)
$$

By (16) and (14) the sliding mode control of PUMA 560 robot manipulator is calculated as;

$$
\begin{array}{r}
U=\left[D^{-1}(f+C+G)+\dot{S}\right] D+K \\
\cdot S G N(S / \varnothing)
\end{array}
$$

FUZZY LOGIC THEORY: Zadeh introduced fuzzy sets in 1965. After 40 years, fuzzy systems have been widely used in different fields, especially on control problems. Fuzzy systems transfer expert knowledge to mathematical models. Fuzzy systems used fuzzy logic to estimate dynamics of our systems. Fuzzy controllers including fuzzy if-then rules are used to control our systems. However the application area for fuzzy control is really wide, the basic form for all command types of controllers consists of;

- Input fuzzification (binary-to-fuzzy[B/F]conversion)

- Fuzzy rule base (knowledge base)

- Inference engine

- Output defuzzification binary[F/B]conversion) [30-40].

(fu zzy-to-

The basic structure of a fuzzy controller is shown in Figure 1.

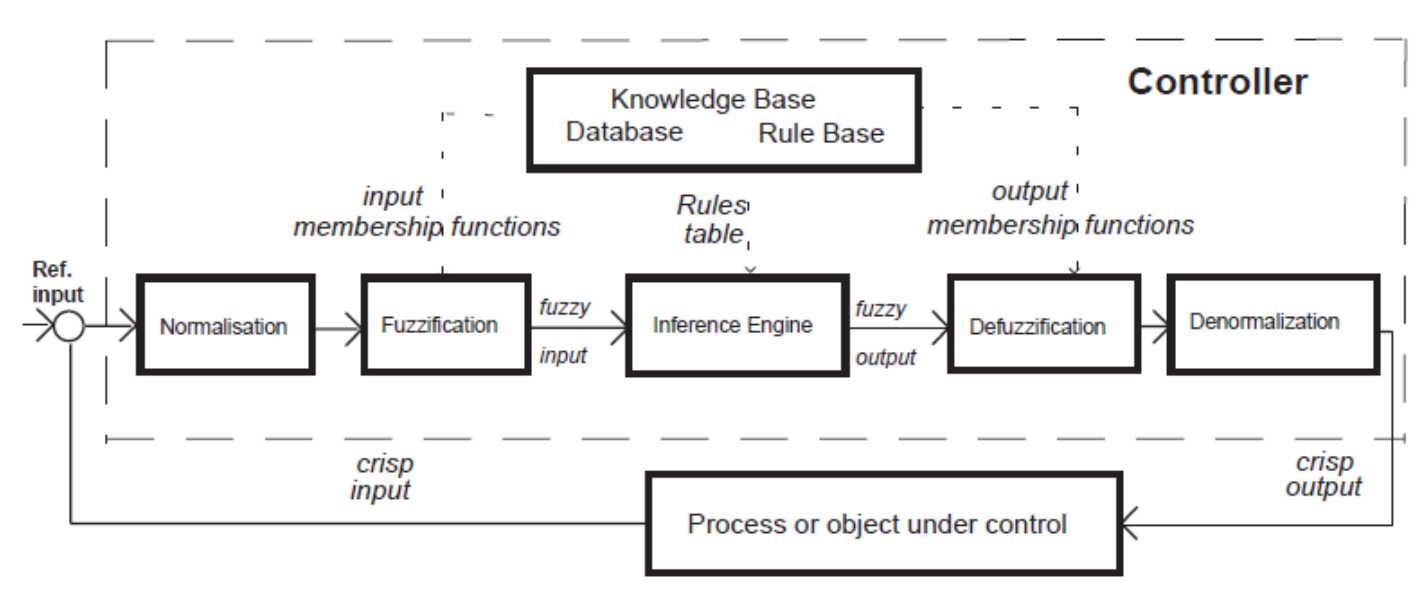

Fig. 1. Block diagram of a fuzzy controller with details.

Conventional control methods use mathematical models to controls systems. Fuzzy control methods replace the mathematical models with fuzzy if then-rules and fuzzy membership function to controls systems. Both fuzzy and conventional control methods are designed to meet system requirements of stability and convergence. When mathematical models are unknown or partially unknown, fuzzy control models can used fuzzy systems to estimate the unknown models. This is called the model-free approach [31, 35]. Conventional control models can use adaptive control methods to achieve the model-free approach. When system dynamics become more complex, nonlinear systems are difficult to handle by conventional control methods. Fuzzy systems can approximate arbitrary nonlinear systems. In practical problems, systems can be controlled perfectly by expert. Experts provide linguistic description about systems. Conventional control methods cannot design controllers combined with linguistic information. When linguistic information is important for designing controllers, we need to design fuzzy controllers for our systems. Fuzzy control methods are easy to understand for designers. The design process of fuzzy controllers can be simplified with simple mathematical models. We define fuzzy systems as two different types. The firs type of fuzzy systems is given by

$$
f(x)=\sum_{l=1}^{M} \theta^{l} \mathcal{E}^{l}(x)=\theta^{T} \mathcal{E}(x)
$$

Where

$\theta=\left(\theta^{1}, \ldots, \theta^{M}\right)^{T}, \mathcal{E}(x)=$ $\left(\mathcal{E}^{1}(x), \ldots, \mathcal{E}^{M}(x)\right)^{T}$, and $\mathcal{E}^{l}(x)=$ $: \prod_{i=1}^{n} \frac{{ }_{A_{i}^{l}}\left(x_{i}\right)}{} \sum_{l=1}^{M}\left(\prod_{i=1}^{n} \mu_{A_{i}^{l}}\left(x_{i}\right)\right) \cdot \theta^{1}, \ldots, \theta^{M}$ are adjustable parameters in (18). $\mu_{A_{1}^{1}}\left(x_{1}\right), \ldots, \mu_{A_{n}^{m}}\left(x_{n}\right)$ are given membership functions whose parameters will not change over time. 
The second type of fuzzy systems is given by

$$
=\frac{\sum_{l=1}^{M} \theta^{l}\left[\prod_{i=1}^{n} \exp \left(-\left(\frac{x_{i}-\alpha_{i}^{l}}{\delta_{i}^{l}}\right)^{2}\right)\right]}{\sum_{l=1}^{M}\left[\prod_{i=1}^{n} \exp \left(-\left(\frac{x_{i}-\alpha_{i}^{l}}{\delta_{i}^{l}}\right)^{2}\right)\right]}
$$

Where $\theta^{l}, \alpha_{i}^{l}$ and $\delta_{i}^{l}$ are all adjustable parameters.

From the universal approximation theorem, we know that we can find a fuzzy system to estimate any continuous function. For the first type of fuzzy systems, we can only adjust $\theta^{l}$ in (18). We define $f^{\wedge}(x \mid \theta)$ as the approximator of the real function $f(x)$.

$$
f^{\wedge}(x \mid \theta)=\theta^{T} \varepsilon(x)
$$

We define $\theta^{*}$ as the values for the minimum error:

$$
\theta^{*}=\arg \min _{\theta \in \Omega}\left[\sup _{x \in U}\left|f^{\wedge}(x \mid \theta)-g(x)\right|\right]
$$

Where $\Omega$ is a constraint set for $\theta$. For specific $x, \sup _{x \in U}\left|f^{\wedge}\left(x \mid \theta^{*}\right)-f(x)\right|$ is the minimum approximation error we can get.

We used the first type of fuzzy systems (18) to estimate the nonlinear system (23) the fuzzy formulation can be write as below;

$$
\begin{aligned}
\boldsymbol{f}(\boldsymbol{x} \mid \boldsymbol{\theta}) & =\boldsymbol{\theta}^{T} \varepsilon(x) \\
& =\frac{\sum_{l=1}^{n} \theta^{l}\left[\mu_{A^{l}}(x)\right]}{\sum_{l=1}^{n}\left[\mu_{A^{l}}(x)\right]}
\end{aligned}
$$

Where $\theta^{1}, \ldots, \theta^{n}$ are adjusted by an adaptation law. The adaptation law is designed to minimize the parameter errors of $\theta-\theta^{*}$.
DYNAMIC FORMULATION OF CONTINUUM ROBOT: The Continuum section analytical model developed here consists of three modules stacked together in series. In general, the model will be a more precise replication of the behavior of a continuum arm with a greater of modules included in series. However, we will show that three modules effectively represent the dynamic behavior of the hardware, so more complex models are not motivated. Thus, the constant curvature bend exhibited by the section is incorporated inherently within the model. The model resulting from the application of Lagrange's equations of motion obtained for this systemcan be represented in the form

$$
F_{\text {coeff }} \underline{\tau}=D(\underline{q}) \underline{\ddot{q}}+C(\underline{q}) \underline{\dot{q}}+G(\underline{q})
$$

where $\tau$ is a vector of input forces and $\mathrm{q}$ is a vector of generalized co-ordinates. The force coefficient matrix $F_{\text {coeff }}$ transforms the input forces to the generalized forces and torques in the system. The inertia matrix, $D$ is composed of four block matrices. The block matrices that correspond to pure linear accelerations and pure angular accelerations in the system (on the top left and on the bottom right) are symmetric. The matrix $C$ contains coefficients of the first order derivatives of the generalized co-ord inates. Since the system is nonlinear, many elements of $C$ contain first order derivatives of the generalized co-ordinates. The remaining terms in the dynamic equations resulting from gravitational potential energies and spring energies are collected in the matrix $G$. The coefficient matrices of the dynamic equations are given below,

$$
\begin{aligned}
& \text { Fcoeff }= \\
& {\left[\begin{array}{cccccc}
1 & 1 & \cos \left(\theta_{1}\right) & \cos \left(\theta_{1}\right) & \cos \left(\theta_{1}+\theta_{2}\right) & \cos \left(\theta_{1}+\theta_{2}\right) \\
0 & 0 & 1 & 1 & \cos \left(\theta_{2}\right) & \cos \left(\theta_{2}\right) \\
0 & 0 & 0 & 0 & 1 & 1 \\
1 / 2 & -1 / 2 & 1 / 2 & -1 / 2 & 1 / 2+s_{2} \sin \left(\theta_{2}\right) & -1 / 2+s_{2} \sin \left(\theta_{2}\right) \\
0 & 0 & 1 / 2 & -1 / 2 & 1 / 2 & -1 / 2 \\
0 & 0 & 0 & 0 & 1 / 2 & -1 / 2
\end{array}\right]}
\end{aligned}
$$

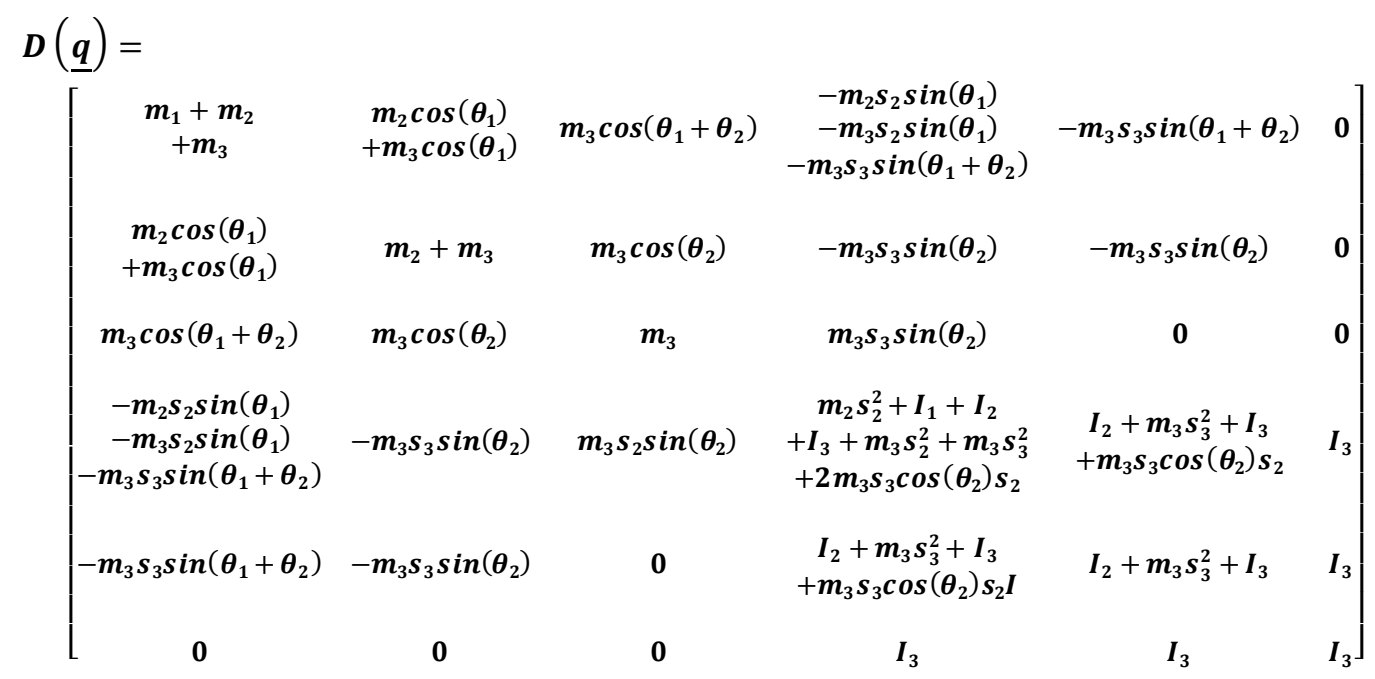




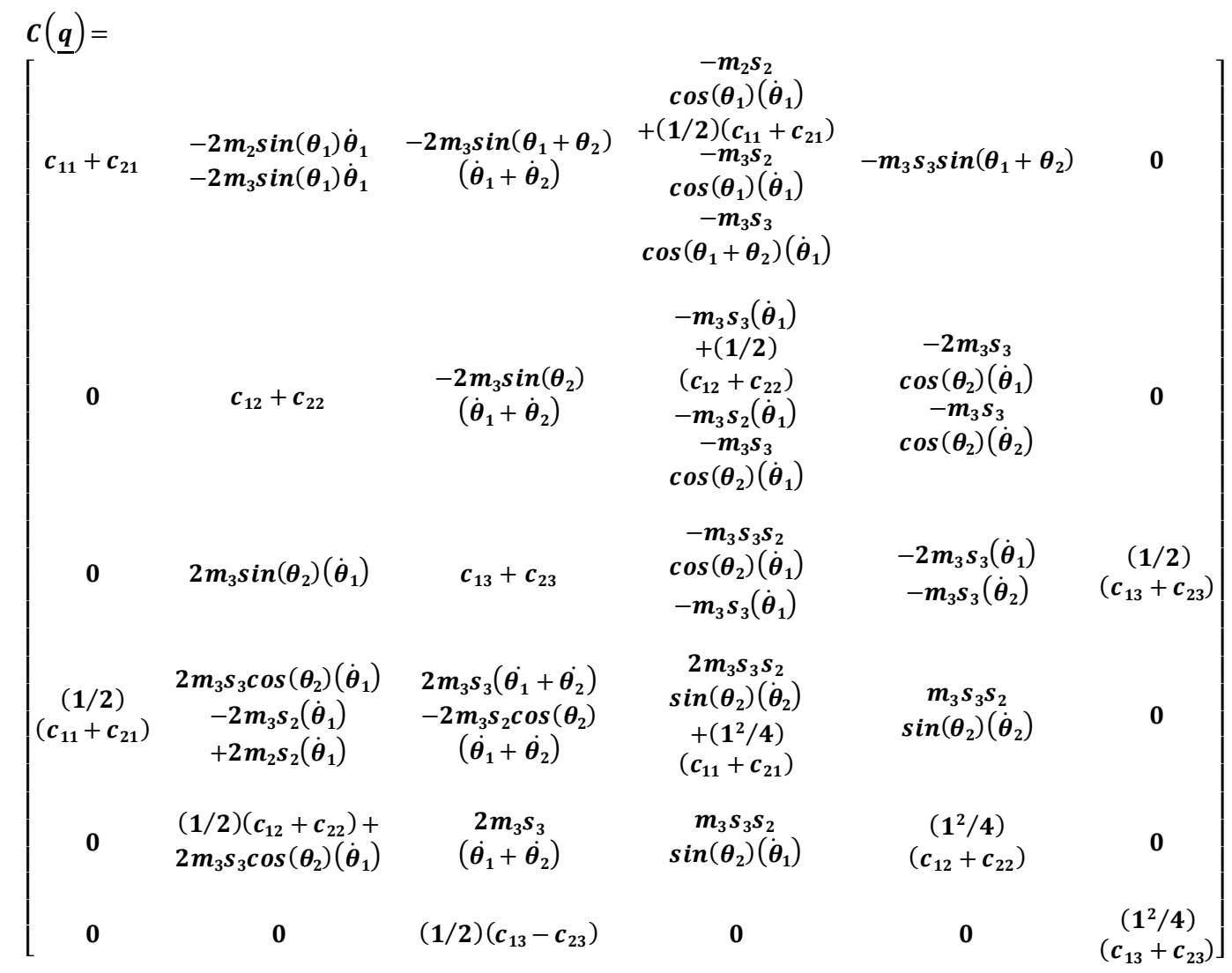

$G(\underline{q})=$

$$
\left.\begin{array}{c}
{\left[\begin{array}{c}
-m_{1} g-m_{2} g+k_{11}\left(s_{1}+(1 / 2) \theta_{1}-s_{01}\right)+k_{21}\left(s_{1}-(1 / 2) \theta_{1}-s_{01}\right)-m_{3} g \\
-m_{2} g \cos \left(\theta_{1}\right)+k_{12}\left(s_{2}+(1 / 2) \theta_{2}-s_{02}\right)+k_{22}\left(s_{2}-(1 / 2) \theta_{2}-s_{02}\right)-m_{3} g \cos \left(\theta_{1}\right) \\
-m_{3} g \cos \left(\theta_{1}+\theta_{2}\right)+k_{13}\left(s_{3}+(1 / 2) \theta_{3}-s_{03}\right)+k_{23}\left(s_{3}-(1 / 2) \theta_{3}-s_{03}\right) \\
m_{2} s_{2} g \sin \left(\theta_{1}\right)+m_{3} s_{3} g \sin \left(\theta_{1}+\theta_{2}\right)+m_{3} s_{2} g \sin \left(\theta_{1}\right)+k_{11}\left(s_{1}+(1 / 2) \theta_{1}-s_{01}\right)(1 / 2) \\
+k_{21}\left(s_{1}-(1 / 2) \theta_{1}-s_{01}\right)(-1 / 2)
\end{array}\right.} \\
m_{3} s_{3} g \sin \left(\theta_{1}+\theta_{2}\right)+k_{12}\left(s_{2}+(1 / 2) \theta_{2}-s_{02}\right)(1 / 2)+k_{22}\left(s_{2}-(1 / 2) \theta_{2}-s_{02}\right)(-1 / 2) \\
k_{13}\left(s_{3}+(1 / 2) \theta_{3}-s_{03}\right)(1 / 2)+k_{23}\left(s_{3}-(1 / 2) \theta_{3}-s_{03}\right)(-1 / 2)
\end{array}\right]
$$

\section{METHODOLOGY}

If the dynamic equation of an m-link robotic manipulator is

$$
D(\boldsymbol{q}) \ddot{\boldsymbol{q}}+\boldsymbol{V}(\boldsymbol{q}, \dot{\boldsymbol{q}})+\boldsymbol{G}(\boldsymbol{q})=\boldsymbol{\tau}
$$

Where $q=\left[q_{1}, \ldots, q_{m}\right]^{T}$ is an $m \times 1$ vector of joint position, $M(q)$ is an $m \times m$ inertial matrix, $c(q, \dot{q})$ is an $m \times 1$ matrix of Coriolis and centrifugal forces, $G(q)$ is an $m \times 1$ gravity vector and $\tau=\left[\tau_{1}, \ldots, \tau_{m}\right]^{T}$ is an $m \times 1$ vector of joint torques. This paper proposed an adaptive fuzzy sliding mode control scheme applied to a robotic manipulator. A MIMO (multi-input multi-output) fuzzy system is designed to compensate the uncertainties of the robotic manipulator. The parameters of the fuzzy systemare adjusted by adaptation laws.

The tracking error and the sliding surface state are defined as the previous formulation
We define the reference state as

$$
\begin{aligned}
& \dot{\boldsymbol{q}}_{r}=\dot{\boldsymbol{q}}-\boldsymbol{s}=\dot{\boldsymbol{q}}_{d}-\lambda \boldsymbol{e} \\
& \ddot{\boldsymbol{q}}_{r}=\ddot{\boldsymbol{q}}-\dot{\boldsymbol{s}}=\ddot{\boldsymbol{q}}_{d}-\lambda \dot{e}
\end{aligned}
$$

The general MIMO if-then rules are given by

$$
\begin{gathered}
R^{l} \text { : if } x_{1} \text { is } A_{1}^{l}, x_{2} \text { is } A_{2}^{l}, \ldots, x_{n} \text { is } A_{n}^{l}, \\
\text { then } y_{1} \text { is } B_{1}^{l}, \ldots, y_{m} \text { is } B_{m}^{l}
\end{gathered}
$$

Where $l=1,2, \ldots, M$ are fuzzy if-then rules; $x=$ $\left(x_{1}, \ldots, x_{n}\right)^{T}$ and $y=\left(y_{1}, \ldots, y_{n}\right)^{T}$ are the input and output vectors of the fuzzy system. The MIMO fuzzy systemis define as

$$
f(x)=\ominus^{T} \varepsilon(x)
$$


Where

$$
\ominus^{T}=\left(\theta_{1}, \ldots, \theta_{m}\right)^{T}=\left[\begin{array}{c}
\theta_{1}^{1}, \theta_{1}^{2}, \ldots, \theta_{1}^{M} \\
\theta_{2}^{1}, \theta_{2}^{2}, \ldots, \theta_{2}^{M} \\
\vdots \\
\theta_{m}^{1}, \theta_{m}^{2}, \ldots, \theta_{m}^{M}
\end{array}\right]
$$

$\varepsilon(x)=\left(\varepsilon^{1}(x), \ldots, \varepsilon^{M}(x)\right)^{T}, \quad \varepsilon^{1}(x)=\prod_{i=1}^{n} \mu_{A_{i}^{l}}\left(x_{i}\right) /$

$\sum_{l=1}^{M}\left(\prod_{i=1}^{n} \mu_{A_{i}^{l}}\left(x_{i}\right)\right)$, and $\mu_{A_{i}^{l}}\left(x_{i}\right)$ is defined in (22). To reduce the number of fuzzy rules, we divide the fuzzy systemin to three parts:

$$
\begin{aligned}
F^{1}(q, \dot{q}) & =\ominus^{1^{T}} \varepsilon(q, \dot{q}) \\
& =\left[\theta_{1}^{1^{T}} \varepsilon(q, \dot{q}), \ldots, \theta_{m}^{1^{T}} \varepsilon(q, \dot{q})\right]^{T} \\
F^{2}\left(q, \ddot{q}_{r}\right) & =\ominus^{2^{T}} \varepsilon\left(q, \ddot{q}_{r}\right) \\
& =\left[\theta_{1}^{2^{T}} \varepsilon\left(q, \ddot{q}_{r}\right), \ldots,{\theta_{m}^{2}}^{T} \varepsilon\left(q, \ddot{q}_{r}\right)\right]^{T} \\
F^{3}(q, \ddot{q}) & =\ominus^{3^{T}} \varepsilon(q, \ddot{q}) \\
& =\left[\theta_{1}^{3^{T}} \varepsilon(q, \dot{q}), \ldots, \theta_{m}^{3^{T}} \varepsilon(q, \ddot{q})\right]^{T}
\end{aligned}
$$

The control input is given by

$$
\begin{aligned}
& \tau=D^{\wedge} \ddot{q}_{r}+C_{1}^{\wedge} \dot{q}_{r}+G^{\wedge}+F^{1}(q, \dot{q})+ \\
& F^{2}\left(q, \ddot{q}_{r}\right)+F^{3}(q, \ddot{q})-K_{D} s-W s g n(s)
\end{aligned}
$$

Where $M^{\wedge}, C_{1}^{\wedge}$ are the estimations of $M(q)$ and $C_{1}(q, \dot{q}) ; K_{D}=\operatorname{diag}\left[K_{D 1}, \ldots, K_{D m}\right]$ and $K_{D 1}, \ldots, K_{D m}$ are positive constants; $W=\operatorname{diag}\left[W_{1}, \ldots, W_{m}\right]$ and $W_{1}, \ldots, W_{m}$ are positive constants. The adaptation law is given by

$$
\begin{aligned}
\dot{\theta}_{j}^{1} & =-\Gamma_{1 j} s_{j} \varepsilon(q, \dot{q}) \\
\dot{\theta}_{j}^{2} & =-\Gamma_{2 j} s_{j} \varepsilon\left(q, \ddot{q}_{r}\right) \\
\dot{\theta}_{j}^{3} & =-\Gamma_{3 j} s_{j} \varepsilon(q, \ddot{q})
\end{aligned}
$$

Where $j=1, \ldots, m$ and $\Gamma_{1 j}-\Gamma_{3 j}$ are positive diagonal matrices.

The Lyapunov function candidate is presented as

$$
\begin{aligned}
& V=\frac{1}{2} s^{T} D s+\frac{1}{2} \sum_{j=1}^{m} \frac{1}{\Gamma_{1 j}} \emptyset_{j}^{1^{T}} \emptyset_{j}^{1}+ \\
& \frac{1}{2} \sum_{j=1}^{m} \frac{1}{\Gamma_{2 j}} \emptyset_{j}^{2^{T}} \emptyset_{j}^{2}+\frac{1}{2} \sum_{j=1}^{m} \frac{1}{\Gamma_{3 j}} \emptyset_{j}^{13^{T}} \emptyset_{j}^{3}
\end{aligned}
$$

Where $\emptyset_{j}^{1}=\emptyset_{j}^{1^{*}}-\emptyset_{j}^{1}, \emptyset_{j}^{2}=\emptyset_{j}^{2^{*}}-\emptyset_{j}^{2}$ and $\emptyset_{j}^{3}=\emptyset_{j}^{3^{*}-}$ $\emptyset_{j}^{3}$ we define

$$
\begin{aligned}
& \boldsymbol{F}\left(\boldsymbol{q}, \dot{\boldsymbol{q}}, \ddot{\boldsymbol{q}}_{r}, \ddot{\boldsymbol{q}}\right)=\boldsymbol{F}^{\mathbf{1}}(\boldsymbol{q}, \dot{\boldsymbol{q}})+\boldsymbol{F}^{2}\left(\boldsymbol{q}, \ddot{\boldsymbol{q}}_{r}\right)+ \\
& \boldsymbol{F}^{3}(\boldsymbol{q}, \ddot{\boldsymbol{q}})
\end{aligned}
$$

From (28), we get

$$
\begin{aligned}
& D(q) \ddot{q}+C_{1}(q, \dot{q}) \dot{q}+G(q)=M^{\wedge} \ddot{q}_{r}+ \\
& C_{1}^{\wedge} \dot{q}_{r}+G^{\wedge}+F\left(q, \dot{q}, \ddot{q}_{r}, \ddot{q}\right)-K_{D} s- \\
& W s g n(s)
\end{aligned}
$$

Since $\dot{q}_{r}=\dot{q}-s$ and $\ddot{q}_{r}=\ddot{q}-\dot{s}$, we get

$$
\begin{aligned}
& D \dot{s}+\left(C_{1}+K_{D}\right) s+W \operatorname{sgn}(s)=-\Delta F+ \\
& F\left(q, \dot{q}, \ddot{q}_{r}, \ddot{q}\right)
\end{aligned}
$$

Then $D \dot{s}+C_{1} s$ can be written as

$$
\begin{aligned}
& D \dot{s}+C_{1} s=-\Delta F+F\left(q, \dot{q}, \ddot{q}_{r}, \ddot{q}\right)-K_{D} s- \\
& W \operatorname{sgn}(s)
\end{aligned}
$$

Where $\quad \Delta F=\widetilde{D} \ddot{q}_{r}+\tilde{C}_{1} \dot{q}_{r}+\tilde{G}, \widetilde{D}=D-D^{\wedge}, \tilde{C}_{1}=$ $C_{1}-\tilde{C}_{1}$ and $\tilde{G}=G-G^{\wedge}$.

The derivative of $V$ is

$$
\begin{aligned}
& \dot{V}=s^{T} D \dot{s}+\frac{1}{2} s^{T} \dot{D} s+\sum_{j=1}^{m} \frac{1}{\Gamma_{1 j}} \emptyset_{j}^{1^{T}} \dot{\emptyset}_{j}^{1}+ \\
& \sum_{j=1}^{m} \frac{1}{\Gamma_{2 j}} \phi_{j}^{2^{T}} \dot{\phi}_{j}^{2}+\sum_{j=1}^{m} \frac{1}{\Gamma_{3 j}} \phi_{j}^{13^{T}} \dot{\emptyset}_{j}^{3}
\end{aligned}
$$

We know that $s^{T} D \dot{s}+\frac{1}{2} s^{T} \dot{D} s=s^{T}\left(D \dot{s}+C_{1} s\right)$ from (46). Then

$$
\begin{aligned}
& \dot{V}=-s^{T}\left[-K_{D} s+W \operatorname{sgn}(s)+\Delta F-\right. \\
& \left.F\left(q, \dot{q}, \ddot{q}_{r}, \ddot{q}\right)\right]+\sum_{j=1}^{m} \frac{1}{\Gamma_{1 j}} \emptyset_{j}^{1^{T}} \dot{\phi}_{j}^{1}+ \\
& \sum_{j=1}^{m} \frac{1}{\Gamma_{2 j}} \emptyset_{j}^{2^{T}} \dot{\phi}_{j}^{2}+\sum_{j=1}^{m} \frac{1}{\Gamma_{3 j}} \emptyset_{j}^{13^{T}} \dot{\emptyset}_{j}^{3}
\end{aligned}
$$

We define the minimum approximation error as

$$
\begin{aligned}
& \boldsymbol{\omega}= \\
& \Delta \boldsymbol{F}-\left[\boldsymbol{F}^{\mathbf{1}}\left(\boldsymbol{q}, \dot{\boldsymbol{q}} \mid \ominus^{1^{*}}\right)+\boldsymbol{F}^{2}\left(\boldsymbol{q}, \ddot{\boldsymbol{q}}_{r} \mid \ominus^{2^{*}}\right)+\right. \\
& \left.\boldsymbol{F}^{3}\left(\boldsymbol{q}, \ddot{\boldsymbol{q}} \mid \ominus^{3^{*}}\right)\right]
\end{aligned}
$$

We plug (48) in to (47)

$$
\begin{aligned}
& \dot{V}= \\
& -s^{T}\left[-K_{D} s+\right. \\
& W \operatorname{sgn}(s)+ \\
& \Delta \boldsymbol{F}- \\
& \left.\boldsymbol{F}\left(\boldsymbol{q}, \dot{\boldsymbol{q}}, \ddot{\boldsymbol{q}}_{r}, \ddot{\boldsymbol{q}}\right)\right]+ \\
& \sum_{j=1}^{m} \frac{1}{\Gamma_{1 j}} \emptyset_{j}^{1^{T}} \dot{\emptyset}_{j}^{1}+ \\
& \sum_{j=1}^{m} \frac{1}{\Gamma_{2 j}} \emptyset_{j}^{2^{T}} \dot{\emptyset}_{j}^{2}+ \\
& \sum_{j=1}^{m} \frac{1}{\Gamma_{3 j}} \emptyset_{j}^{13^{T}} \dot{\emptyset}_{j}^{3} \\
& =-s^{T}\left[-K_{D^{2}} s+W \operatorname{sgn}(s)+\omega+\right. \\
& F^{1}\left(q, \dot{q} \mid \ominus^{1^{*}}\right)+F^{2}\left(q, \ddot{q}_{r} \mid \ominus^{2^{*}}\right)+ \\
& F^{3}\left(q, \ddot{q} \mid \ominus^{3^{*}}\right)-F^{1}(q, \dot{q})+F^{2}\left(q, \ddot{q}_{r}\right)+ \\
& \left.F^{3}(q, \ddot{q})\right]+\sum_{j=1}^{m} \frac{1}{\Gamma_{1 j}} \emptyset_{j}^{1^{T}} \dot{\emptyset}_{j}^{1}+ \\
& \sum_{j=1}^{m} \frac{1}{\Gamma_{2 j}} \emptyset_{j}^{2^{T}} \dot{\emptyset}_{j}^{2}+\sum_{j=1}^{m} \frac{1}{\Gamma_{3 j}} \emptyset_{j}^{13^{T}} \dot{\emptyset}_{j}^{3} \\
& =-s^{T} K_{D_{T}} s-s^{T} W \operatorname{sgn}(s)-s^{T} \omega- \\
& \sum_{j=1}^{m} s_{j} \emptyset_{j}^{1^{T}} \varepsilon(q, \dot{q})-\sum_{j=1}^{m} s_{j} \emptyset_{j}^{2^{T}} \varepsilon\left(q, \ddot{q}_{r}\right)- \\
& \sum_{j=1}^{m} s_{j} \emptyset_{j}^{3^{T}} \varepsilon(q, \ddot{q})+\sum_{j=1}^{m} \frac{1}{\Gamma_{1 j}} \emptyset_{j}^{1^{T}} \dot{\emptyset}_{j}^{1}+ \\
& \sum_{j=1}^{m} \frac{1}{\Gamma_{2 j}} \emptyset_{j}^{2^{T}} \dot{\emptyset}_{j}^{2}+\sum_{j=1}^{m} \frac{1}{\Gamma_{3 j}} \emptyset_{j}^{3^{T}} \dot{\emptyset}_{j}^{3} \\
& = \\
& -s^{T} K_{D} s-s^{T} W \operatorname{sgn}(s)- \\
& s^{T} \omega- \\
& \sum_{j=1}^{m} \emptyset_{j}^{1^{T}}\left(s_{j} \varepsilon(q, \dot{q})-\right. \\
& \left.\frac{1}{\Gamma_{1 j}} \dot{\emptyset}_{j}^{1}\right)-
\end{aligned}
$$




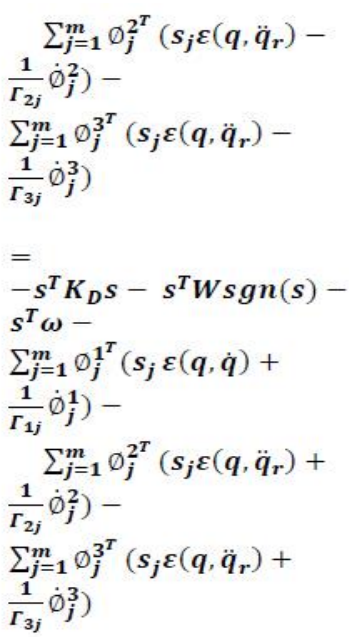

The adaptation laws are chosen as becomes

$$
\begin{aligned}
\dot{V} & =-s_{m}^{T} K_{D} s-s^{T} W \operatorname{sgn}(s)-s^{T} \omega \\
& =-\sum_{j=1}^{m}\left(s_{j}^{2} K_{D j}+W_{j}\left|s_{j}\right|+s_{j} \omega_{j}\right)
\end{aligned}
$$

$$
=-\sum_{j=1}^{m}\left[s_{j}\left(s_{j} K_{D j}+\omega_{j}\right)+W_{j}\left|s_{j}\right|\right]
$$

Since $\omega_{j}$ can be as small as possible, we can find $K_{D j}$ that $\left|s_{j}^{2} K_{D j}\right|>\left|\omega_{j}\right|\left(s_{j} \neq 0\right)$.

Therefore, we can get $s_{j}\left(s_{j} K_{D j}+\omega_{j}\right)>0$ for $s_{j} \neq 0$ and $\dot{V}<0(s \neq 0)$.

Figure 2 is shown the proposed method.

$$
s^{T}\left(\dot{D}-2 C_{1}\right) s=0
$$

Then $\dot{V}$ becomes

$$
\begin{aligned}
\dot{V} & =s^{T} D \dot{s}+\frac{1}{2} s^{T} \dot{D} s \\
& =s^{T}\left(D \dot{s}+C_{1} s\right) \\
& =s^{T}[-A s+\Delta f-K \operatorname{sgn}(s)] \\
& =\sum_{i=1}^{2}\left(s_{i}\left[\Delta f_{i}-K_{i} \operatorname{sgn}\left(s_{i}\right)\right]\right)-s^{T} A s
\end{aligned}
$$

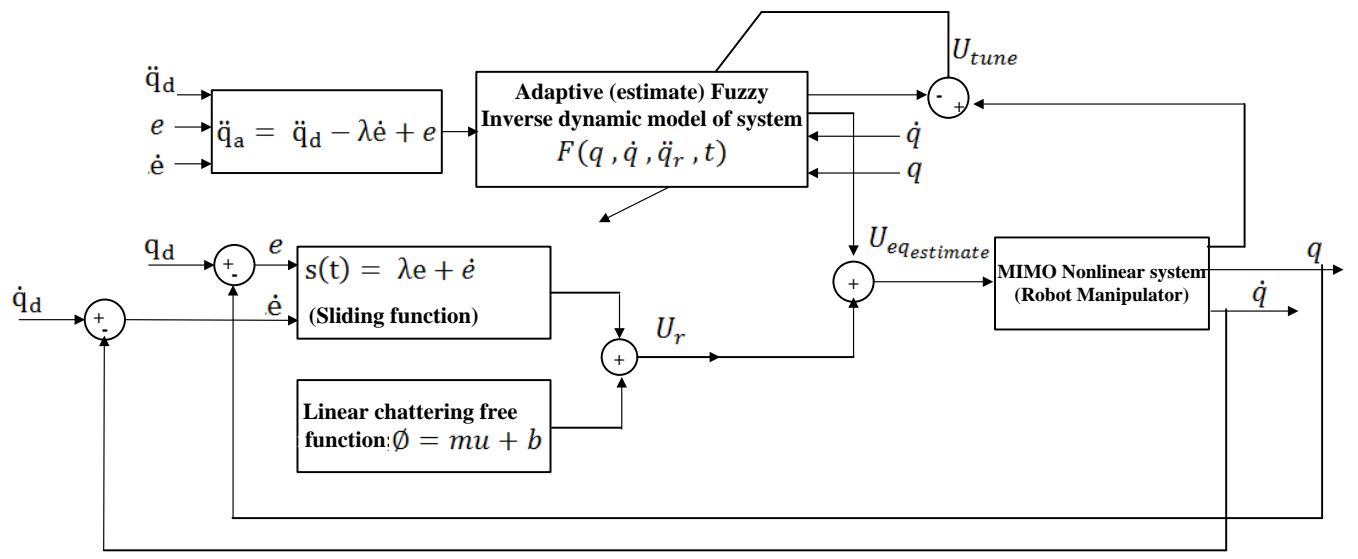

Fig. 2. Adaptive MIMO Fuzzy Compensate Fuzzy Sliding Mode Algorithm

For $K_{i} \geq\left|\Delta f_{i}\right|$, we always get $s_{i}\left[\Delta f_{i}-K_{i} \operatorname{sgn}\left(s_{i}\right)\right] \leq$ 0 . We can describe $\dot{V}$ as

$$
\begin{aligned}
& \dot{V}=\sum_{i=1}^{2}\left(s _ { i } \left[\Delta f_{i}\right.\right.\left.\left.-K_{i} \operatorname{sgn}\left(s_{i}\right)\right]\right)-s^{T} A s \\
& \leq-s^{T} A s<0(s \neq 0)
\end{aligned}
$$

\section{RESULT AND DISCUSSION}

Sliding mode controller (SMC) and adaptive MIMO fuzzy compensate fuzzy sliding mode controller (AFCFSMC) are implemented in Matlab/Simulink environment. Tracking performance, disturbance rejection and error are compared.

Tracking performances: From the simulation for first and second trajectory without any disturbance, it was seen that both of controllers have the same performance, because these controllers are adjusted and worked on certain environment. Figure 3 is shown tracking performance in certain system and without external disturbance these two controllers.

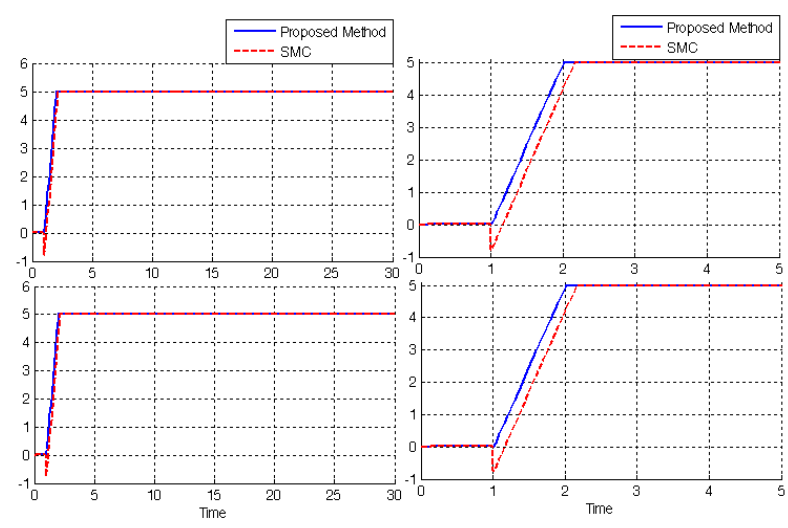

Fig. 3. SMC Vs. AFCFSMC: applied to first 2 DOF serial robot manipulator 
By comparing trajectory response in above graph it is found that the AFCFSMC undershoot (0\%) is lower than SMC (13.8\%), although both of them have about the same overshoot.

Disturbance rejection: Figure 4 has shown the power disturbance elimination in above controllers. The main targets in these controllers are disturbance rejection as well as the other responses. A band limited white noise with predefined of $40 \%$ the power of input signal is applied to controllers. It found fairly fluctuations in SMC trajectory responses.
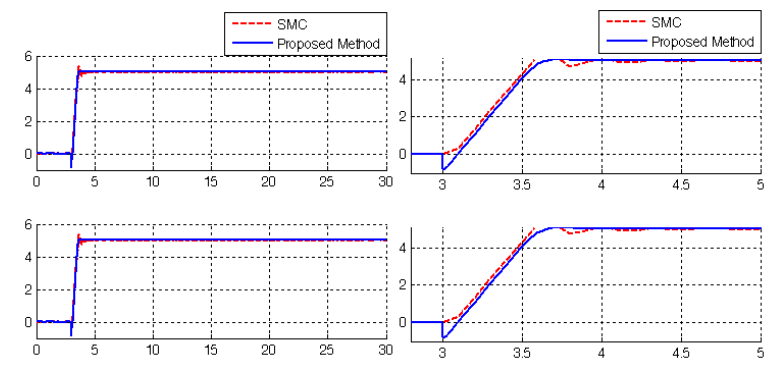

Fig. 4. SMC Vs. AFCFSMC in presence of uncertainty and external disturbance: applied to first 2DOF serial robot manipulator

Among above graph relating to trajectory following with external disturbance, SMC has fairly fluctuations. By comparing some control parameters such as overshoot and rise time it found that the AFCFSMC's overshoot $\mathbf{( 0 \% )}$ is lower than SMC's $\mathbf{( 6 \% )}$, although both of them have about the same rise time.

Calculate errors: Figure 6 has shown the error disturbance in above controllers. The controllers with no external disturbances have the same error response. By comparing the steady state error and RMS error it found that the AFCFSMC's errors (Steady State error = 0.000007 and RMS error $=0.000008$ ) are fairly less than FLC's (Steady State error $\cong \mathbf{0 . 0 0 1 2}$ and RMS error=0.0018), When disturbance is applied to the SMC error is about $23 \%$ growth.
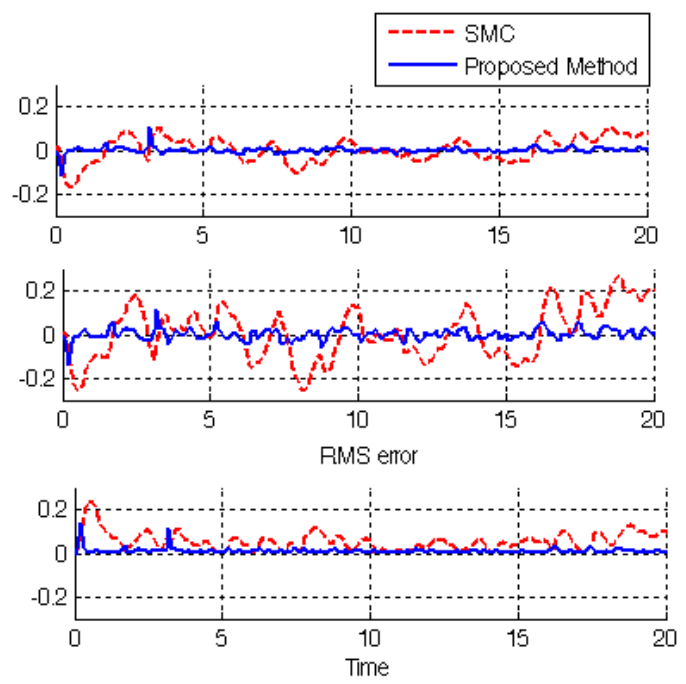

Fig. 5. SMC Vs. AFCFSMC (error performance): applied to first 2DOF serial robot manipulator

\section{CONCLUSION}

Adaptive fuzzy sliding mode control algorithm for robot manipulators is investigated in this paper. Proposed algorithm utilizes MIMO fuzzy system to estimate the cross-coupling effects in robotic manipulator and gets perfect tracking accuracy. However, the switching control term in the control law causes chattering and there is no methodology to tune the premise part of the fuzzy rules. Proposed algorithm attenuated the chattering problem very well by substituting a fuzzy compensator and saturation function for the switching control term. The number of fuzzy rules is also reduced by abandoning MIMO fuzzy systems and SISO fuzzy systems instead. But we still need to predefine the premise part of the fuzzy rules. The stability and the convergence of this algorith $\mathrm{ms}$ for the $\mathrm{m}$-lin $\mathrm{k}$ continuum robotic manipulator is proved theoretically using Lyapunov stability theory. Proposed algorithm has predefined adaptation gains in the adaptation laws which are highly related to the performance of our controllers. In this method the tuning part is applied to consequence part, in the case of the mlink robotic manipulator, if we define $k_{1}$ membership functions for each input variable, the number of fuzzy rules applied for each joint is $3 k_{1}^{2 m}$ and eliminate the chattering based on stable switching methodology.

\section{ACKNOWLEDGMENT}

The authors would like to thank the anonymous reviewers for their careful reading of this paper and for their helpful comments. This work was supported by the Institute of Advanced Science and Technology (IRANSSP) Research and Development Corporation Program of Iran undergrant no. 2013-Persian Gulf-2B.

\section{REFERENCES}

[1] T. R. Kurfess, Robotics and automation handbook: CRC, 2005.

[2] J. J. E. Slotine and W. Li, Applied nonlinear control vol. 461: Prentice hall Englewood Cliffs, NJ, 1991.

[3] L. Cheng, et al., "Multi-agent based adaptive consensus control for multiple manipulators with kinematic uncertainties," 2008, pp. 189-194.

[4] J. J. D'Azzo, et al., Linear control system analysis and design with MATLAB: CRC, 2003.

[5] B. Siciliano and O. Khatib, Springer handbook of robotics: Springer-Verlag New York Inc, 2008.

[6] I. Boiko, et al., "Analysis of chattering in systems with second-order sliding modes," IEEE Transactions on Automatic Control, vol. 52, pp. 2085-2102, 2007.

[7] J. Wang, et al., "Indirect adaptive fuzzy sliding mode control: Part I: fuzzy switching," Fuzzy Sets and Systems, vol. 122, pp. 21-30, 2001.

[8] F. Piltan, et al., "Artificial Control of Nonlinear Second Order Systems Based on AFGSMC," Australian Journal of Basic and Applied Sciences, 5(6), pp. 509-522, 2011.

[9] V. Utkin, "Variable structure sy stems with sliding modes," Automatic Control, IEEE Transactions on, vol. 22, pp. 212-222, 2002. 
[10] R. A. DeCarlo, et al., "Variable structure control of nonlinear multivariable sy stems: a tutorial," Proceedings of the IEEE, vol. 76, pp. 212-232, 2002.

[11] K. D. Young, et al., "A control en gineer's guide to sliding mode control," 2002, pp. 1-14.

[12] Samira Soltani \& Farzin Piltan, "Design Artificial Nonlinear Controller Based on Computed Torque like Controller with Tunable Gain", World Applied Science Journal (WASJ), 14 (9): 1306-1312, 2011.

[13] Farzin Piltan, Mohammadali Dialame, Abbas Zare \& Ali Badri,"Design Novel Lookup Table Changed Auto Tuning FSMC:Applied to Robot Manipulator", International Journal of Engineering, 6 (1):25-41, 2012

[14] Farzin Piltan, Mohammad Keshavarz, Ali Badri \& Arash Zargari,"Design Novel Nonlinear Controller Applied to RobotManipulator: Design New Feedback Linearization Fuzzy Controller with Minimum Rule Base Tuning Method", International Journal of Robotics and Automation,3 (1):1-12, 2012

[15] Farzin Piltan, Iman Nazari, Sobhan Siamak, Payman Ferdosali,"Methodology of FPGA-Based Mathematical error-Based Tuning Sliding Mode Controller", International Journal of Control and Automation, 5(1), 89118,2012

[16] Farzin Piltan, Bamdad Boroomand, Arman Jahed \& Hossein Rezaie, "Methodology of Mathematical ErrorBased Tuning Sliding Mode Controller", International Journal of Engineering, 6 (2):96-117, 2012

[17] Farzin Piltan, Sara Emamzadeh, Zahra Hivand, Fatemeh Shahriyari \& Mina Mirazaei, "PUMA-560 Robot Manipulator Position Sliding Mode Control Methods Using MATLAB/SIMULINK and Their Integration into Graduate/Undergraduate Nonlinear Control, Robotics and MATLAB Courses", International Journal of Robotics and Automation, 3(3):106-150, 2012

[18] Farzin Piltan, Ali Hosainpour, Ebrahim Mazlomian, Mohammad Shamsodini, Mohammad H. Yarmahmoudi, "Online Tuning Chattering Free Sliding Mode Fuzzy Control Design: Lyapunov Approach", International Journal of Robotics and Automation, 3(3):77105,2012

[19] Farzin Piltan, Mina Mirzaei, Forouzan Shahriari, Iman Nazari, Sara Emamzadeh, "Design Baseline Computed Torque Controller", International Journal of Engineering, 6(3): 129-141, 2012

[20] Farzin Piltan, Mohammad H. Yarmahmoudi, Mohammad Shamsodini, Ebrahim Mazlomian, Ali Hosainpour, "PUMA-560 Robot Manipulator Position Computed Torque Control Methods Using MATLAB/SIMULINK and Their Integration into Graduate Nonlinear Control and MATLAB Courses", International Journal of Robotics and Automation, 3(3): 167-191, 2012

[21] Farzin Piltan, Hossein Rezaie, Bamdad Boroomand, Arman Jahed, "Design Robust Backstepping on-line Tuning Feedback Linearization Control Applied to IC Engine", International Journal of Advance Science and Technology, 11:40-22, 2012

[22] Farzin Piltan, Mohammad R. Rashidian, Mohammad Shamsodini and Sadeq Allahdadi, Effect of Rule Base on the Fuzzy-Based Tuning Fuzzy Sliding Mode Controller: Applied to $2^{\text {nd }}$ Order Nonlinear System", International Journal of Advanced Science and Technology, 46:39-70, 2012

[23] Farzin Piltan, Arman Jahed, Hossein Rezaie and Bamdad Boroomand, "Methodology of Robust Linear On-line High Speed Tuning for Stable Sliding Mode Controller: Applied to Nonlinear System", International Journal of Control and Automation, 5(3): 217-236, 2012

[24] Farzin Piltan, Bamdad Boroomand, Arman Jahed and Hossein Rezaie, "Performance-Based Adaptive Gradient Descent Optimal Coefficient Fuzzy Sliding Mode Methodology", International Journal of Intelligent Systems and Applications, , vol.4, no.11, pp.40-52, 2012.

[25] Farzin Piltan, Mehdi Akbari, Mojdeh Piran , Mansour Bazregar, "Design Model Free Switching Gain Scheduling Baseline Controller with Application to Automotive Engine", International Journal of Information Technology and Computer Science, vol.5, no.1, pp.65-73, 2013.DOI: 10.5815/ijitcs.2013.01.07.

[26] Farzin Piltan, Mojdeh Piran, Mansour Bazregar, Mehdi Akbari, "Design High Impact Fuzzy Baseline Variable Structure Methodology to Artificial Adjust Fuel Ratio", International Journal of Intelligent Systems and Applications, vol.5, no.2, pp.59-70, 2013.DOI: 10.5815/ijisa.2013.02.0.

[27] Farzin Piltan, M. Bazregar, M. kamgari, M. Akbari and M. Piran, "Adjust the Fuel Ratio by High Impact Chattering Free Sliding Methodology with Application to Automotive Engine", International Journal of Hybrid Information Technology, 6(1), 2013.

[28] Farzin Piltan, S. Zare , F. ShahryarZadeh, M. Mansoorzadeh, M. kamgari, "Supervised Optimization of Fuel Ratio in IC Engine Based on Design Baseline Computed Fuel Methodology", International Journal of Information Technology and Computer Science, vol.5, no.4, pp.76-84, 2013.DOI: 10.5815/ijitcs.2013.04.09.

[29] Farzin Piltan, M. Mansoorzadeh, S. Zare, F.Shahry arzadeh, M. Akbari, "Artificial Tune of Fuel Ratio: Design a Novel SISO Fuzzy Backstepping Adaptive Variable Structure Control", International Journal of Electrical and Computer Engineering, 3(2), 2013.

[30] M. Bazregar, Farzin Piltan, A. Nabaee and M.M. Ebrahimi, "Parallel Soft Computing Control Optimization Algorithm for Uncertainty Dynamic Systems", International Journal of Advanced Science and Technology, 51, 2013.

[31] Farzin Piltan, M.H. Yarmahmoudi, M. Mirzaei, S. Emamzadeh, Z. Hivand, "Design Novel Fuzzy Robust Feedback Linearization Control with Application to Robot Manipulator", International Journal of Intelligent Systems and Applications , vol.5, no.5, pp.1-10, 2013.DOI: 10.5815/ijisa.2013.05.01.

[32] Sh. Tay ebi Haghighi, S. Soltani, Farzin Piltan, M. kamgari, S. Zare, "Evaluation Performance of IC Engine: Linear Tunable Gain Computed Torque Controller Vs. Sliding Mode Controller", International Journal of Intelligent Systems and Applications, vol.5, no.6, pp.78-88, 2013.DOI: 10.5815/ijisa.2013.06.10.

[33] Amin Jalali, Farzin Piltan, M. Keshtgar, M. Jalali, "Colonial Competitive Optimization Sliding Mode Controller with Application to Robot Manipulator", International Journal of Intelligent Systems and Applications, vol.5, no.7, pp.50-56, 2013. DOI: 10.5815/ijisa.2013.07.07.

[34] Salehi, Farzin Piltan, M. Mousavi, A. Khajeh, M. R. Rashidian, "Intelligent Robust Feed-forward Fuzzy Feedback Linearization Estimation of PID Control with Application to Continuum Robot", International Journal of Information Engineering and Electronic Business, vol.5, no.1, pp.1-16,2013. DOI: 10.5815/ijieeb.2013.01.01.

[35] Farzin Piltan, M.J. Rafaati, F. Khazaeni, A. Hosainpour, S. Soltani, “A Design High Impact Ly apunov Fuzzy PD-PlusGravity Controller with Application to Rigid Manipulator", International Journal of Information Engineering and 
Electronic Business, vol.5, no.1, pp.17-25, 2013. DOI: 10.5815/ijieeb.2013.01.02.

[36] Amin Jalali, Farzin Piltan, A. Gavahian, M. Jalali, M. Adibi, "Model-Free Adaptive Fuzzy Sliding Mode Controller Optimized by Particle Swarm for Robot manipulator", International Journal of Information Engineering and Electronic Business, vol.5, no.1, pp.68-78, 2013. DOI: 10.5815/ijieeb.2013.01.08.

[37] Farzin Piltan, F. ShahryarZadeh ,M. Mansoorzadeh ,M. kamgari, S. Zare, "Robust Fuzzy PD Method with Parallel Computed Fuel Ratio Estimation Applied to Automotive Engine“, International Journal of Intelligent Systems and Applications, vol.5, no.8, pp.83-92, 2013. DOI: 10.5815/ijisa.2013.08.10.

[38] Farzin Piltan, A. Nabaee, M.M. Ebrahimi, M. Bazregar, "Design Robust Fuzzy Sliding Mode Control Technique for Robot Manipulator Systems with Modeling Uncertainties", International Journal of Information Technology and Computer Science, vol.5, no.8, pp.123135, 2013. DOI: 10.5815/ijitcs.2013.08.12.

[39] Farzin Piltan, M. Mansoorzadeh, M. Akbari, S. Zare, F. ShahryarZadeh "Management of Environmental Pollution by Intelligent Control of Fuel in an Internal Combustion Engine" Global Journal of Biodiversity Science And Management, 3(1), 2013.

[40] M. M. Ebrahimit Farzin Piltan, M. Bazregar and A.R. Nabaee, "Intelligent Robust Fuzzy-Parallel Optimization Control of a Continuum Robot Manipulator", International Journal of Control and Automation, 6(3), 2013.

[41] O.R. Sadrnia, Farzin Piltan, M. Jafari, M. Eram and M. Shamsodini, "Design PID Estimator Fuzzy plus Backstepping to Control of Uncertain Continuum Robot", International Journal of Hybrid Information Technology, 6(4), 2013.

[42] AminJalali, Farzin Piltan, H. Hashemzadeh, A. Hasiri, M.R Hashemzadeh, "Design Novel Soft Computing Backstepping Controller with Application to Nonlinear Dynamic Uncertain System", International Journal of Intelligent Systems and Applications, vol.5, no.10, pp.93105, 2013. DOI: $10.5815 /$ ijisa.2013.10.12.

[43] M. Moosavi, M. Eram, A. Khajeh, O. Mahmoudi and Farzin Piltan, "Design New Artificial Intelligence Base Modified PID Hybrid Controller for Highly Nonlinear System", International Journal of Advanced Science and Technology, 57, 2013.

[44] S. Zahmatkesh, Farzin Piltan, K. Heidari, M. Shamsodini, S. Heidari, "Artificial Error Tuning Based on Design a Novel SISO Fuzzy Backstepping Adaptive Variable Structure Control" International Journal of Intelligent Systems and Applications, vol.5, no.11, pp.34-46, 2013. DOI: $10.5815 /$ ijisa.2013.11.04.

[45] S. Heidari, Farzin Piltan, M. Shamsodini, K. Heidari and S. Zahmatkesh, "Design New Nonlinear Controller with Parallel Fuzzy Inference System Compensator to Control of Continuum Robot Manipulator",International Journal of Control and Automation, 6(4), 2013.

[46] FarzinPiltan, M. Kamgari, S. Zare, F. ShahryarZadeh, M. Mansoorzadeh, "Design Novel Model Reference Artificial Intelligence Based Methodology to Optimized Fuel Ratio in IC Engine", International Journal of Information Engineering and Electronic Business, vol.5, no.2, pp.44-51, 2013. DOI: 10.5815/ijieeb.2013.02.07.

[47] Farzin Piltan, Mehdi Eram, Mohammad Taghavi, Omid Reza Sadrnia, Mahdi Jafari,"Nonlinear Fuzzy Model-base Technique to Compensate Highly Nonlinear Continuum Robot Manipulator", IJISA, vol.5, no.12, pp.135-148, 2013. DOI: $10.5815 /$ ijisa.2013.12.12
[48] Amin Jalali, Farzin Piltan, Mohammadreza Hashemzadeh, Fatemeh Bibak Varavi, Hossein Hashemzadeh,"Design Parallel Linear PD Compensation by Fuzzy Sliding Compensator for Continuum Robot", IJITCS, vol.5, no.12, pp.97-112, 2013. DOI: 10.5815/ijitcs.2013.12.12

[49] Farzin Piltan, A. Hosainpour, S. Emamzadeh, I. Nazari, M. Mirzaie, "Design Sliding Mode Controller of with Parallel Fuzzy Inference System Compensator to Control of Robot Manipulator", International Journal of Robotics and Automation, Vol. 2, No. 4, December 2013, pp. 149 162.

[50] Farzin Piltan, Mahdi Jafari, Mehdi Eram, Omid Mahmoudi, Omid Reza Sadrnia, "Design Artificial Intelligence-Based Switching PD plus Gravity for Highly Nonlinear Second Order System", International Journal of Engineering and Manufacturing, vol.3, no.1, pp.38-57, 2013.DOI: 10.5815/ijem.2013.01.04

[51] Farzin Piltan, Sara Emamzadeh, Sara Heidari, Samaneh Zahmatkesh, Kamran Heidari, "Design Artificial Intelligent Parallel Feedback Linearization of PID Control with Application to Continuum Robot", International Journal of Engineering and Manufacturing, vol.3, no.2, pp.51-72, 2013.DOI: 10.5815/ijem.2013.02.04

[52] Mohammad Mahdi Ebrahimi, Farzin Piltan, Mansour Bazregar, AliReza Nabaee,"Artificial Chattering Free online Modified Sliding Mode Algorithm: Applied in Continuum Robot Manipulator", International Journal of Information Engineering and Electronic Business, vol.5, no.5, pp.57-69, 2013. DOI: 10.5815/ijieeb.2013.05.08

[53] Arman Jahed, Farzin Piltan, Hossein Rezaie, Bamdad Boroomand, "Design Computed Torque Controller with Parallel Fuzzy Inference System Compensator to Control of Robot Manipulator", International Journal of Information Engineering and Electronic Business, vol.5, no.3, pp.66-77, 2013. DOI: 10.5815/ijieeb.2013.03.08

[54] Mohammad Shamsodini, Farzin Piltan, Mahdi Jafari, Omid reza Sadrnia, Omid Mahmoudi,"Design Modified Fuzzy Hybrid Technique: Tuning By GDO", IJMECS, vol.5, no.8, pp.58-72, 2013.DOI: 10.5815/ijmecs.2013.08.07

[55] Mahdi Mirshekaran, Farzin Piltan, Zahra Esmaeili, Tannaz Khajeaian,Meysam Kazeminasab,"Design Sliding Mode Modified Fuzzy Linear Controller with Application to Flexible Robot Manipulator", IJMECS, vol.5, no.10, pp.53-63, 2013.DOI: 10.5815/ijmecs.2013.10.07

\section{Authors' Profiles}

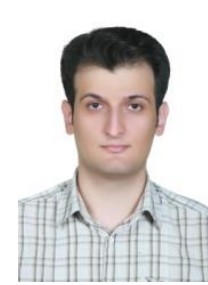

Alireza Khalilian is currently working as a primary researcher in the laboratory of Control and Robotic, Institute of Advance Science and Technology, IRAN SSP research and development Center. His current research interests are in the area of nonlinear control, artificial control system and robotics.

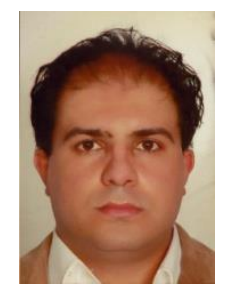

Farzin Piltan was born on 1975, Shiraz, Iran. In 2004 he is jointed Institute of Advance Science and Technology, Research and Development Center, IRAN SSP. Now he is a dean of Intelligent Control and Robotics Lab. In addition to 7 textbooks, Farzin Piltan is the main author of more than 100 scientific papers in refereed journals. He is editorial review board member for 'international journal of control and automation (IJCA), Australia, ISSN: 2005-4297; 'International Journal of Intelligent System and Applications (IJISA)', Hong 
Kong, ISSN:2074-9058; 'IAES international journal of robotics and automation, Malaysia, ISSN:2089-4856; 'International Journal of Reconfigurable and Embedded Systems', Malaysia, ISSN:2089-4864. His current research interests are nonlinear control, artificial control system and applied to FPGA, robotics and artificial nonlinear control and IC engine modeling and control.

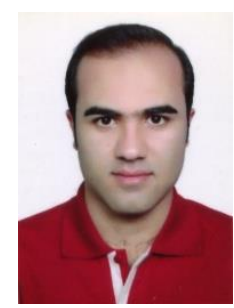

Omid Avatefipour is currently working as a primary researcher in the laboratory of Control and Robotic, Institute of Advance Science and Technology, IRAN SSP research and development Center. His current research interests are in the area of nonlinear control, artificial control system and robotics.

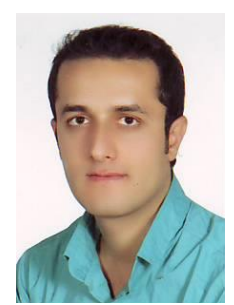

Mahmoud Reza Safaei Nasrabad is currently working as a primary researcher in the laboratory of Control and Robotic, Institute of Advance Science and Technology, IRAN SSP research and development Center. His current research interests are in the area of nonlinear control, artificial control system and robotics.

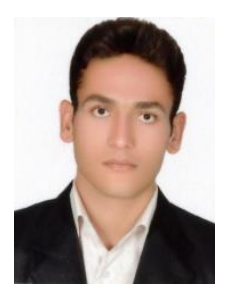

Ghasem Sahamijoo is currently working as a primary researcher in the laboratory of Control and Robotic, Institute of Advance Science and Technology, IRAN SSP research and development Center. His current research interests are in the area of nonlinear control, artificial control system and robotics.

How to cite this paper: Alireza Khalilian, Farzin Piltan, Omid Avatefipour, Mahmoud Reza Safaei Nasrabad, Ghasem Sahamijoo,"Design New Online Tuning Intelligent Chattering Free Fuzzy Compensator", International Journal of Intelligent Systems and Applications(IJISA), vol.6, no.9, pp.75-86, 2014. DOI: $10.5815 /$ ijisa.2014.09.10 